\title{
Five-year follow-up of participants diagnosed with chronic airflow obstruction in a South African Burden of Obstructive Lung Disease (BOLD) survey
}

\author{
B W Allwood, ${ }^{1,2} \mathrm{PhD}$; R Gillespie,${ }^{1} \mathrm{MSc}$ (Nursing); M Bateman, ${ }^{1} \mathrm{MD}$; H Olckers, ${ }^{1}$ BTech Hons; $\mathbf{L}$ Taborda-Barata, ${ }^{3} \mathrm{PhD}$; \\ G L Calligaro, ${ }^{1} \mathrm{MD}$; R van Zyl-Smit, ${ }^{1} \mathrm{PhD}$; C B Cooper, ${ }^{4} \mathrm{PhD}$; N Beyers, ${ }^{4} \mathrm{PhD}$; E D Bateman, ${ }^{1} \mathrm{PhD}$ \\ ${ }^{1}$ Division of Pulmonology, Department of Medicine, Faculty of Health Sciences, University of Cape Town, South Africa; and University of \\ Cape Town Lung Institute, South Africa \\ ${ }^{2}$ Division of Pulmonology, Department of Medicine, Faculty of Medicine and Health Sciences, Stellenbosch University, Cape Town, South Africa \\ ${ }^{3}$ CICS - Health Sciences Research Centre, University of Beira Interior, Portugal \\ ${ }^{4}$ David Geffen School of Medicine, University of California, Los Angeles, USA; and Desmond Tutu TB Centre, Department of Paediatrics and \\ Child Health, Faculty of Medicine and Health Sciences, Stellenbosch University, Cape Town, South Africa
}

Corresponding author: B W Allwood (brianallwood@gmail.com)

\begin{abstract}
Background. A community-based prevalence survey performed in two suburbs in Cape Town, South Africa (SA), in 2005, using the international Burden of Obstructive Lung Disease (BOLD) method, confirmed a prevalence of chronic airflow obstruction (CAO) in 23.1\% of adults aged $>40$ years.

Objectives. To study the clinical course and prognosis over 5 years of patients with CAO identified in the 2005 survey.

Methods. Patients with CAO in 2005 were invited to participate. Standard BOLD and modified questionnaires were completed. Spirometry was performed using spirometers of the same make as in 2005.

Results. Of 196 eligible participants from BOLD 2005, 45 (23.0\%) had died, 8 from respiratory causes, 10 from cardiovascular causes and 6 from other known causes, while in 21 cases the cause of death was not known. On multivariate analysis, only age and Global initiative for Obstructive Lung Disease (GOLD) stage 4 disease at baseline were significantly associated with death. Of the 151 survivors, 11 (5.6\% of the original cohort) were unavailable and $33(16.8 \%)$ declined or had medical exclusions. One hundred and seven survivors were enrolled in the follow-up study (54.6\%, median age 63.1 years, $45.8 \%$ males). Post-bronchodilator spirometry performed in 106 participants failed to confirm CAO, defined as a forced expiratory volume in 1 second $\left(\mathrm{FEV}_{1}\right)$ /forced vital capacity $(\mathrm{FVC})$ ratio of $<0.7$, in 16 participants $(15.1 \%)$, but $\mathrm{CAO}$ was present in 90 . The median decline in $\mathrm{FEV}_{1}$ was $28.9 \mathrm{~mL} /$ year (interquartile range $-54.8-0.0$ ) and was similar between GOLD stages. The median total decline in FVC was $75 \mathrm{~mL}$, and was significantly greater in GOLD stage $1(-350 \mathrm{~mL})$ than in stages 2 or $3(-80 \mathrm{~mL}$ and $+140 \mathrm{~mL}$, respectively; $p<0.01)$. Fifty-eight participants with CAO in $2005(64.4 \%)$ remained in the same GOLD stage, while $21(23.3 \%)$ deteriorated and $11(12.2 \%)$ improved by $\geq 1$ stage. Only one-third were receiving any treatment for chronic obstructive pulmonary disease (COPD).

Conclusions. The prevalence, morbidity and mortality of CAO and COPD in SA are high and the level of appropriate treatment is very low, pointing to underdiagnosis and inadequate provision of and access to effective treatments and preventive strategies for this priority chronic non-communicable disease.
\end{abstract}

S Afr Med J 2018;108(2):138-143. DOI:10.7196/SAMJ.2018.v108i2.12688

Chronic obstructive pulmonary disease (COPD) is recognised as among the top five causes of death globally, and rates are declining more slowly than for other chronic non-communicable diseases. More than $90 \%$ of these deaths occur in low- and middle-income countries. ${ }^{[1-4]}$ COPD is a progressive disease, and in adults lung function, measured as forced expiratory volume in 1 second $\left(\mathrm{FEV}_{1}\right)$, declines more rapidly than is associated with normal ageing, particularly in continuing smokers. ${ }^{[5]}$ However, disease progression is variable, some patients experiencing rapid and others slow deterioration. ${ }^{[6]}$ In many adults with chronic airflow obstruction (CAO), lung function may have been low since earlier decades owing to sub-normal lung development resulting from respiratory infections, malnutrition, factors associated with poverty, parental smoking and other exposure to atmospheric pollutants, and even adverse intrauterine factors. Longitudinal surveys of COPD progression suggest that the rate of lung function loss is greater in individuals with lesser degrees of airflow obstruction. ${ }^{[7-9]}$
In South Africa (SA), a Burden of Obstructive Lung Disease (BOLD) study performed in two low- to middle-income suburbs of Cape Town in 2005 confirmed a very high prevalence of CAO (Global initiative for Obstructive Lung Disease (GOLD) stage $\geq 2$ ) in both men and women aged $\geq 40$ years; $22.2 \%$ of men and $16.7 \%$ of women had evidence of $\mathrm{CAO}$, compared with a global average of $10.1 \%$ in similar studies performed in countries with a range of socioeconomic status. ${ }^{[10,11]}$ In the SA cohort, the most significant risk factors for $\mathrm{CAO}$ were tobacco (cigarette) smoking, a past history of pulmonary tuberculosis (PTB), occupational exposures and a history of asthma. Further analyses of global experience have confirmed this association of previous PTB and COPD, but it does not alone account for the high prevalence of CAO in SA. ${ }^{[12]}$ Faced with this heavy burden of CAO in SA, it is important to better understand its causes, clinical manifestations and course, and the prospects for prevention and treatment. 


\section{Objectives}

To assess the clinical outcome, including mortality, and current management of participants 5 years after they were identified as having CAO in the BOLD 2005 study.

\section{Methods}

The BOLD 2005 study was performed in Ravensmead and Uitsig, two low- to middle-income suburbs in Cape Town, SA, in adults $>40$ years of age, using a population-based single-stage cluster sample and the BOLD method, comprising standardised questionnaires and spirometry. ${ }^{[11]}$ The population in the follow-up study, performed 5 years later, comprised participants identified in the BOLD study as having $\mathrm{CAO}$, defined as an $\mathrm{FEV}_{1}$ / forced vital capacity (FVC) ratio of $<0.7$. The term CAO rather than COPD was used in the follow-up study in recognition of the fact that in a minority of cases conditions other than smoking-related COPD, e.g. asthma, bronchiectasis or chronic destructive changes of previous PTB, might account for airflow obstruction.

At follow-up, attempts were made by community workers to establish the vital status of all participants either by telephonic consultation or repeated door-to-door visits, and all participants who were traced were invited to participate in the current study. Where participants were no longer present at the residence, information was obtained from other local community members (e.g. neighbours or relatives), and repeated attempts were made to contact and enrol these participants.

Participants who provided informed written consent attended the University of Cape Town Lung Institute, where questionnaires were completed and spirometry was performed. Questionnaires included the standard BOLD questionnaires, the modified Medical Research Council Dyspnoea Score (mMRC) and the St George's Respiratory Questionnaire (SGRQ). Owing to poor literacy in a significant proportion of participants, questionnaires were administered by a trained investigator. The range of the SGRQ score is $0-100$, a higher score indicating more severe disease and a total score of $>25$ considered as the threshold for starting treatment. ${ }^{[3]}$ HIV testing was performed after counselling and obtaining of written consent. Spirometry was performed by trained respiratory technologists in accordance with American Thoracic Society/European Respiratory Society guidelines. Spirometers of the same make (EasyOne ndd, ndd Medical Technologies Inc., USA) as had been used in the 2005 BOLD survey were used in the follow-up study. Spirometers were calibrated daily using a $3 \mathrm{~L}$ syringe, ${ }^{[12,13]}$ and spirometry was performed before and 45 minutes after the inhalation of both $100 \mu \mathrm{g}$ of salbutamol and $80 \mu \mathrm{g}$ of ipratropium bromide, administered via a pressurised metered dose inhaler. Bronchodilator reversibility was defined as an increase in $\mathrm{FEV}_{1}$ of $>200 \mathrm{~mL}$ and $12 \%$ of baseline value. The GOLD severity scale based on $\mathrm{FEV}_{1}$ and expressed as the percentage of predicted $\mathrm{FEV}_{1}$ is as follows: stage $1\left(\mathrm{FEV}_{1} \geq 80 \%\right.$ of predicted), stage 2 (50 - 79\%), stage $3(30-49 \%)$, and stage $4(<30 \%)$. Predicted values for $\mathrm{FEV}_{1}$ were calculated using the National Health and Nutrition Examination Survey (NHANES) III reference equations. ${ }^{[3,14]}$

Participants were excluded if they could not be traced, refused participation, had a condition that contraindicated spirometry or administration of a bronchodilator, or had an additional medical condition likely to affect spirometry. For participants who were reported to have died, two registers (City of Cape Town and South African Medical Research Council databases) were scrutinised for information on the cause of death.

Approval to conduct the study was obtained from the ethics committees of the University of Cape Town (ref. no. 441/2009), Stellenbosch University (ref. no. N/09/11/328) and the City of Cape Town (ref. no. 10165). Data were double-entered into the database, and statistical analysis using appropriate tests for parametric and non-parametric data was performed using Stata version 12.1 (StataCorp, USA).

\section{Results}

The BOLD study of 2005 sampled 847 adults aged $>40$ years. CAO was confirmed in $196(23.1 \%), 34(4.0 \%)$ in GOLD stage 1, 109 $(12.9 \%)$ in stage 2, $48(5.7 \%)$ in stage 3 and $5(0.6 \%)$ in stage 4 . At 5-year follow-up, $45(23.0 \%)$ of the participants with airflow limitation had died. Of the participants who were alive at follow-up, $11(5.6 \%)$ had moved away from the survey area and could not be traced, 19 (9.7\%) declined participation, and 14 (7.1\%) were excluded from participation on medical grounds (5 with dementia, 3 with malignancy and 6 for miscellaneous medical reasons) (Fig. 1).

One hundred and seven patients (54.6\% of the original participants with COPD with airflow limitation) were included in the subsequent analysis, but one further subject was unable to perform spirometry. All the participants identified themselves as 'coloured' (mixed race), ${ }^{[15]}$ and none was HIV-positive. Forty-nine (45.8\%) were men, their median age was 63.1 years (range $46.4-82.7)$, and $13(12.2 \%)$ had never smoked (Table 1). The mean number of pack-years in current smokers $(n=60)$ was similar to that of ex-smokers ( $n=34), 24.8$ and 26.9 pack-years, respectively. Thirty-nine participants (36.5\%) reported a history of previous PTB. Twenty (52.3\%) reported that their first episode of PTB had occurred before the age of 40 years (range 6 - 77) and 13 (33.3\%) reported more than one episode. Ten participants $(9.3 \%)$ reported that they had received treatment for active tuberculosis (TB) during the 5 years between the two studies; in 7 this was a first episode, and in 3 it represented a recurrence. On clinical review, a diagnosis of asthma was made in 18 subjects (17.0\%), of whom 15 had CAO.

The median SGRQ total score at follow-up was 33.4 (interquartile range (IQR) 14.1 - 54.1). This was not measured in the original study. The mMRC dyspnoea score was $\geq 2$ (breathlessness when hurrying on a level or up a slight hill) in $59.8 \%$ of participants at follow-up, with $54.2 \%$ of participants reporting worsening over the 5 -year period and $13.1 \%$ improvement. Sixty-three participants (58.9\%) reported a chronic cough, compared with $48(44.9 \%)$ in the initial study. The majority of the participants $(n=68,63.6 \%)$ reported no use of medications for their lung condition. Less than one-third reported use of short-acting beta-2-agonists, and only four (3.7\%) used a longacting bronchodilator (Table 1).

\section{Mortality}

Of the 45 deaths, 8 (17.8\%) were due to respiratory causes, 10 $(22.2 \%)$ were due to cardiovascular disease and $6(13.3 \%)$ were from miscellaneous causes; the cause of death was unknown in 21 participants ( $46.7 \%$ of deaths) (Fig. 1). The majority of the deaths $(57.7 \%)$ occurred in participants with mild/moderate COPD (i.e. GOLD stages 1 or 2) in the original study. The mean (standard deviation (SD)) age of participants who died was 63.3 (11.2) years, and $24(53.3 \%)$ of the deaths were in men. Death occurred in 6 of 34 participants (17.7\%) who had been designated as in GOLD stage 1 in 2005, 20 of $109(18.3 \%)$ in stage 2,15 of $48(31.3 \%)$ in stage 3 and 4 of $5(80.0 \%)$ in stage 4 . On multivariate analysis, only age $(p=0.003)$ and GOLD stage 4 COPD $(p=0.006)$ were significantly associated with mortality - gender, pack-years of smoking, years of schooling and a history of previous PTB were not (Table 2).

\section{Spirometry}

In the 106 participants who underwent repeat spirometry, the median post-bronchodilator $\mathrm{FEV}_{1}$ was $1.51 \mathrm{~L}$ (IQR 1.12 - 2.13), compared 


\begin{tabular}{|c|c|}
\hline Male, $n(\%)$ & $49(45.8)$ \\
\hline Age (years), median (IQR) & $63.1(55.2-69.8)$ \\
\hline \multicolumn{2}{|l|}{ Smoking status, $n(\%)$} \\
\hline Never smoked & $13(12.2)$ \\
\hline Current smoker & $60(56.1)$ \\
\hline Ex-smoker & $34(31.8)$ \\
\hline \multicolumn{2}{|l|}{ Comorbidity, $n$ (\%) } \\
\hline Hypertension & $52(48.6)$ \\
\hline Heart disease & $15(14.0)$ \\
\hline High cholesterol & $10(9.3)$ \\
\hline Diabetes & $13(12.1)$ \\
\hline Previous cancer & $2(1.9)$ \\
\hline Previous PTB & $39(36.5)$ \\
\hline Diagnosis of asthma & $18(17.0)$ \\
\hline No comorbidity & $34(31.8)$ \\
\hline \multicolumn{2}{|l|}{ Post-bronchodilator lung function $(N=106)$} \\
\hline $\mathrm{FEV}_{1}(\mathrm{~L})$, mean $(\mathrm{SD})$ & $1.63(0.66)$ \\
\hline $\mathrm{FEV}_{1}$ (\% pred.), mean (SD) & $62.7(18.9)$ \\
\hline FVC (L), mean (SD) & $2.86(0.98)$ \\
\hline FVC (\% pred.), mean (SD) & $82.6(15.4)$ \\
\hline $\mathrm{FEV}_{1} / \mathrm{FVC}(\%)$, mean (SD) & $57.5(14.0)$ \\
\hline No longer obstructed, $n(\%)^{*}$ & $16(15.1)$ \\
\hline Participants using respiratory medication, $n(\%)$ & $39(36.5)$ \\
\hline \multicolumn{2}{|l|}{ Medications used, $n$ (\%) } \\
\hline Short-acting beta-2-agonist & $32(29.9)$ \\
\hline Short-acting antimuscarinic & $10(9.4)$ \\
\hline Long-acting beta-2-agonist & $4(3.7)$ \\
\hline Long-acting antimuscarinic & 0 \\
\hline Inhaled corticosteroid & $18(16.8)$ \\
\hline Theophylline & $10(9.4)$ \\
\hline $\begin{array}{l}\text { Participants not receiving respiratory } \\
\text { medication, } n(\%)\end{array}$ & $68(63.6)$ \\
\hline \multicolumn{2}{|c|}{$\begin{array}{l}\mathrm{SD}=\text { standard deviation; } \mathrm{IQR}=\text { interquartile range; } \mathrm{PTB}=\text { pulmonary tuberculosis; } \\
\mathrm{FEV} \text { 抽ced expiratory volume in } 1 \text { second; } \mathrm{FVC}=\text { forced vital capacity; } \% \text { pred. } \\
\text { percentage of predicted. } \\
\text { × } \mathrm{Obstruction} \text { defined as post-bronchodilator } \mathrm{FEV}_{1} / \mathrm{FVC}<0.7 \text {. }\end{array}$} \\
\hline
\end{tabular}

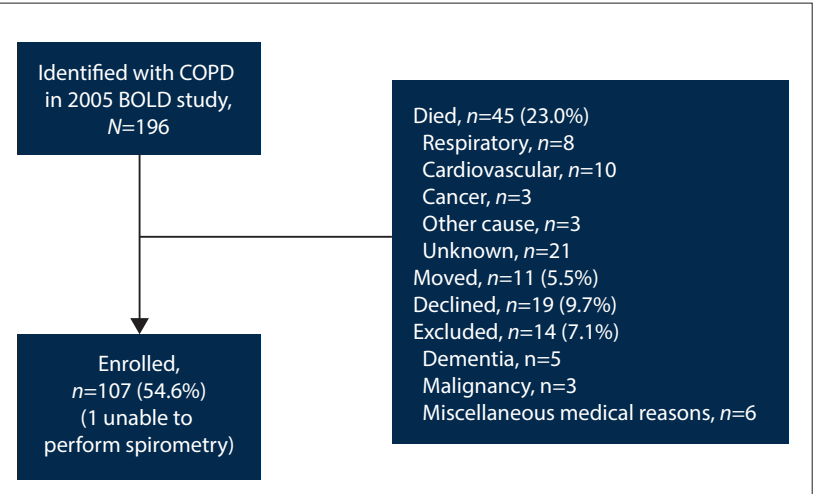

Fig. 1. Follow-up, outcomes and enrolment of participants. (COPD = chronic obstructive pulmonary disease; $B O L D=$ Burden of Obstructive Lung Disease.)

with $1.64 \mathrm{~L}$ (IQR $1.28-2.27$ ) in the baseline study $(p<0.0001)$. There was, however, no difference in the median $\mathrm{FEV}_{1}$ reported as percentage of predicted between the two studies $(62.7 \%$ and $63.8 \%$, respectively; $p=0.316$ ). The corresponding median $\mathrm{FVC}$ values were $2.66 \mathrm{~L}$ (IQR 2.09 - 3.45) and 2.77 L (IQR 2.22 - 3.54), respectively
Table 2. Multivariate analysis of risk factors for mortality

\begin{tabular}{llll}
\hline Variable & OR & $p$-value & $\mathbf{9 5 \% ~ C I ~}$ \\
\hline Age & 1.05 & 0.003 & $1.02-1.09$ \\
Gender: females (males & 0.64 & 0.256 & $0.29-1.38$ \\
were reference) & & & \\
GOLD stage & & & \\
$\quad$ & & & \\
1 & Ref & Ref & Ref \\
2 & 1.11 & 0.845 & $0.38-3.29$ \\
3 & 2.47 & 0.140 & $0.74-8.23$ \\
$\quad 4$ & 29.16 & 0.006 & $2.61-325.22$ \\
Pack-years of smoking & 1.01 & 0.332 & $0.99-1.02$ \\
Years of schooling & 0.90 & 0.106 & $0.80-1.02$ \\
Previous PTB & 1.92 & 0.137 & $0.81-4.58$ \\
OR = odds ratio; CI = confidence interval; GOLD $=$ Global initiative for Obstructive Lung \\
Disease; PTB = pulmonary tuberculosis.
\end{tabular}

( $p=0.0419$ ), and $82.6 \%$ and $82.3 \%$ of the predicted value, respectively ( $p=0.773$ ) (Table 3 and Fig. 2). Bronchodilator reversibility was found in 34 participants $(32.1 \%)$.

In 16 of 106 participants (15.1\%), post-bronchodilator spirometry did not confirm airflow obstruction at the follow-up visit (i.e. $\mathrm{FEV}_{1} / \mathrm{FVC}$ $\geq 0.7$ ). These and a further 11 participants had a post-bronchodilator $\mathrm{FEV}_{1} / \mathrm{FVC}$ ratio above the predicted lower limit of normal, i.e. were not obstructed using the lower limit of normal definition of airflow obstruction. Fifty-nine of the 106 participants (55.6\%), including nine who no longer had airflow obstruction, had an FVC $<80 \%$ of the predicted value, i.e. a restricted lung function pattern.

The comparison of GOLD staging at baseline and follow-up is shown in Table 4. Of the 90 participants with airflow obstruction in 2010, 58 (64.4\%) remained in the same GOLD stage, 21 (23.3\%) had deteriorated and $11(12.2 \%)$ had improved by one GOLD stage.

The median decline in post-bronchodilator $\mathrm{FEV}_{1}$ was $28.9 \mathrm{~mL}$ per year (IQR $-54.8-0.0)$, but expressed as a percentage of predicted $\mathrm{FEV}_{1}$ (corrected for age) was not significant (change $=-1.1$, SD 11.0). No difference in the rate of $\mathrm{FEV}_{1}$ decline by GOLD stage in 2005 was observed.

The median total decline in FVC was $-75 \mathrm{ml}$ (IQR $-420-+200$ ), and similarly was not significantly different when expressed as a percentage of predicted FVC (change $=2.48$, IQR $-9.38-+10.42$ ). However, the decline in median FVC was significantly greater in participants with initial GOLD stage $1(-350 \mathrm{~mL}, \mathrm{IQR}-520-$ $-190)$ compared with GOLD stage $2(-80 \mathrm{~mL}, \mathrm{IQR}-390-+190)$ or GOLD stage $3(+140 \mathrm{~mL}$, IQR $-160-+270)(p<0.01)$. Similar significant differences were observed in median decline when FVC was expressed as a percentage of predicted between the same groups $(-8.5 \%,+2.1 \%$ and $+8.0 \% ; p=0.01)$.

The median $\mathrm{FEV}_{1} / \mathrm{FVC}$ ratio declined by $-2.5 \%$ (SD 9.76; $p=0.005$ ) (Table 3).

In participants reporting previous $\mathrm{PTB}(n=39)$, the median decline in $\mathrm{FEV}_{1}$ was $34.3 \mathrm{~mL} /$ year (IQR -63.6 - +3.6), which was not significantly different from those without previous PTB $(-22.8 \mathrm{~mL} /$ year, IQR $-52.9--4.1 ; p=0.549)$. The 10 participants who contracted TB between the studies showed a median $\mathrm{FEV}_{1}$ decline of $-47.0 \mathrm{~mL} /$ year (IQR -78.0 - -21.2) compared with $-26.7 \mathrm{~mL} /$ year (IQR -51.8 $0.0)$ for the remainder of the participants $(p=0.210)$.

The median FVC decline was less in the 39 participants with a history of PTB than in those without $(+22.8 \mathrm{~mL} /$ year, IQR -50.7 +55.8 v. $-22.2 \mathrm{~mL} /$ year, IQR $-92.4-+24.0 ; p=0.021)$ but not when expressed as percentage of predicted FVC $(p=0.191)$. The median rate of decline in FVC in the 10 participants reporting 
Table 3. Comparison between post-bronchodilator FEV , FVC and FEV, $/ F V C$ ratio between the BOLD and follow-up studies

\begin{tabular}{llll}
\hline & BOLD study & Follow-up study & $p$-value \\
\hline FEV $_{1}(\mathrm{~L})$, median $(\mathrm{IQR})$ & $1.64(1.28-2.27)$ & $1.51(1.12-2.13)$ & $<0.0001$ (Wilcoxon) \\
$\mathrm{FEV}_{1}(\%$ pred.), mean $(\mathrm{SD})$ & $63.8(16.9)$ & $62.7(18.9)$ & 0.316 ( $t$-test for paired samples) \\
FVC (L), median (IQR) & $2.77(2.22-3.54)$ & $2.66(2.09-3.45)$ & 0.0419 (Wilcoxon) \\
FVC (\% pred.), median (IQR) & $82.3(69.1-92.1)$ & $82.6(71.8-94.2)$ & 0.773 (Wilcoxon) \\
FEV $/$ /FVC (\%), median (IQR) & $60.0(55.8-67.2)$ & $57.5(46.1-66.2)$ & 0.0047 (Wilcoxon)
\end{tabular}

$\mathrm{FEV}_{1}=$ forced expiratory volume in 1 second; $\mathrm{FVC}=$ forced vital capacity; $\mathrm{BOLD}=$ Burden of Obstructive Lung Disease; $\mathrm{SD}=$ standard deviation; \% pred. = percentage of predicted value; $\mathrm{IQR}=$ interquartile range; Wilcoxon $=$ Wilcoxon signed-rank test.

\begin{tabular}{|c|c|c|c|c|c|c|}
\hline \multirow{2}{*}{$\begin{array}{l}\text { GOLD stage at } \\
\text { BOLD study }\end{array}$} & \multirow{2}{*}{$\begin{array}{l}\text { Not obstructed, } \\
n(\%)\end{array}$} & \multicolumn{4}{|c|}{ GOLD stage at follow-up study, $n(\%)$} & \multirow[b]{2}{*}{ Total, $N$} \\
\hline & & 1 & 2 & 3 & 4 & \\
\hline 1 & $6(35.3)$ & $6(35.3)$ & $5(29.4)$ & 0 & 0 & 17 \\
\hline 2 & $9(13.8)$ & $6(9.2)$ & 37 (56.9) & $12(18.5)$ & $1(1.5)$ & 65 \\
\hline 3 & $1(4.3)$ & $1(4.3)$ & $3(13.0)$ & $15(65.2)$ & $3(13.0)$ & 23 \\
\hline 4 & 0 & 0 & 0 & $1(100)$ & 0 & 1 \\
\hline Total & $16(15.1)$ & $13(12.2)$ & $45(42.5)$ & $28(26.4)$ & $4(3.7)$ & 106 \\
\hline
\end{tabular}
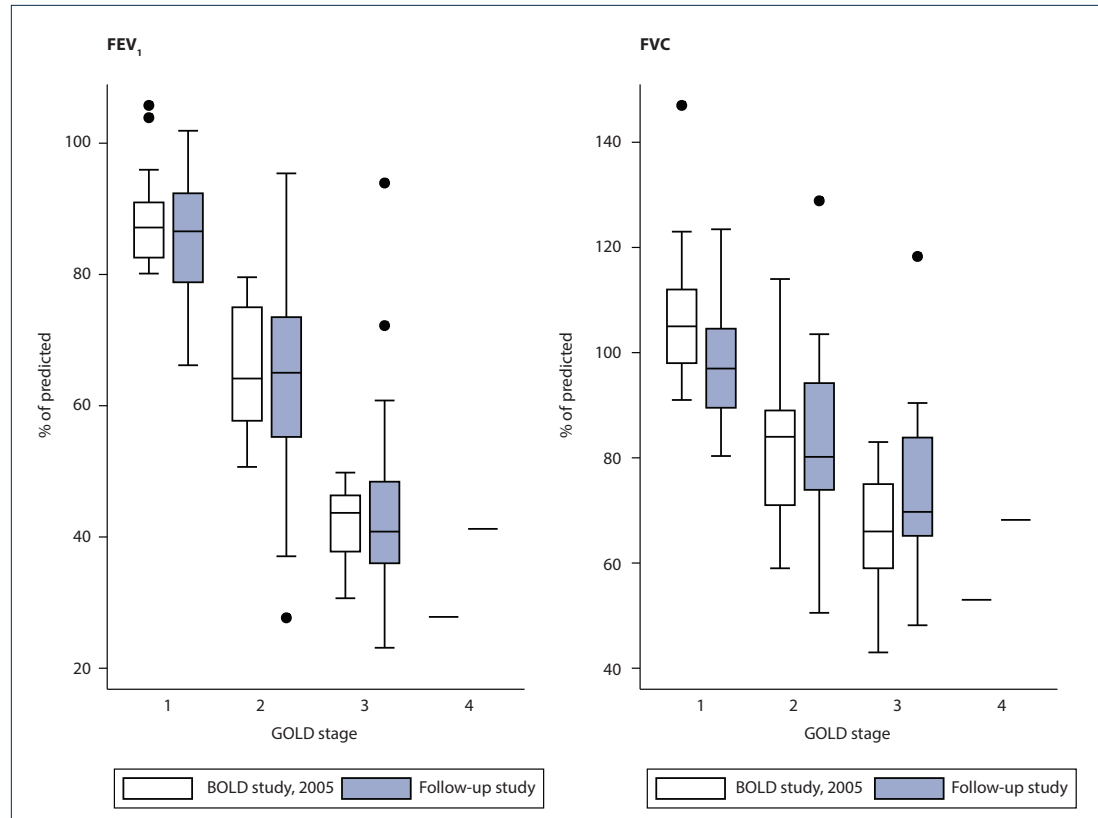

Fig. 2. FEV and FVC as percentage of predicted at BOLD and follow-up studies, according to GOLD (severity) staging at initial study. (FEV $=$ forced expiratory volume in 1 second; $F V C=$ forced vital capacity; $B O L D=$ Burden of Obstructive Lung Disease; GOLD = Global initiative for Obstructive Lung Disease.)

TB during the follow-up period was not statistically different to that of the remainder of the participants $(-17.0$ v. $-11.9 \mathrm{~mL} /$ year; $p=0.589$ ).

\section{Discussion}

This 5-year follow-up study of participants identified with $\mathrm{CAO}$ in a population-based single-stage cluster sample from a low- to middle-income community in Cape Town, SA, although small and underpowered for definitive conclusions, is unique and provides greater detail and reported elsewhere. ${ }^{[16,17]}$ In addition, in this over-40 age group, $\sim 15 \%$ of participants may be considered to have asthma with evidence of $\mathrm{CAO}$ at the time of the original survey. However, the majority of patients in the current study best fit the description of COPD, namely $\mathrm{CAO}$ with a significant history of smoking or similar exposure, with no or minimal evidence of post-PTB scarring on a chest radiograph and lung computed tomography scan.

Within the limitations of a small sample, the mortality rate over 5 years of almost $25 \%$ for a COPD community-based cohort was unexpectedly high compared with the national age-specific death rate for this age group of $\sim 20$ - 35 deaths per 1000 population over the same period. ${ }^{[18]}$ More than half of these deaths occurred in patients previously diagnosed with only mild to moderate COPD, which may be at least partly explained by an excess of non-respiratory causes of death (e.g. cardiovascular deaths). Comorbid disease in COPD is well documented. In the Western Cape Province of SA it was found to occur in up to $88 \%$ of patients with chronic respiratory disease, ${ }^{[19]}$ and it was also common in our participants who survived. Not unexpectedly, older age and very severe airflow obstruction were associated with mortality, but other factors responsible for this high mortality rate were not apparent, and are likely to be varied. However, the SA coloured population has previously been shown to have both a higher prevalence of smoking and a greater smoking-attributed proportion of deaths compared with the other population groups. ${ }^{[20]}$ These and other 
reasons for the high mortality rate in our subjects with CAO need to be further investigated.

In our study, the overall lung function decline measured as $\mathrm{FEV}_{1}$ and FVC followed age-related predictions, which implies a stable trajectory. ${ }^{[6]}$ However, given the high mortality in our study, this might be influenced by a 'healthy survivor' effect, i.e. the death of more rapid decliners. The pattern of decline of lung function between GOLD stages was variable, however, a finding described in other studies. ${ }^{[7,21]}$ The overall decline in FVC was age-appropriate, but was more rapid in the mild and moderate GOLD stages than in participants with more severe impairment $(p<0.01)$. This more rapid lung function decline in early or less severe COPD is consistent with recent findings reported in large epidemiological studies, although at odds with the traditional lung function trajectories proposed by Fletcher and Peto. ${ }^{[5]}$

A further important finding in our study relates to the limitation of spirometry-based population surveys, namely the definitions and cut-offs that define chronic airflow limitation. Fifteen percent of our participants identified with CAO in the 2005 study no longer satisfied the criteria for $\mathrm{CAO}$ at follow-up. Possible reasons include the limited reproducibility of spirometry (3.5\% for calibration) ${ }^{[13]}$ natural intrasubject variation of the measures over time, intercurrent events such as recent respiratory infections, and the presence of asthma. Seventeen percent of the current population were found to have asthma, and significant improvement of $\mathrm{FEV}_{1}$ after dual rapid-acting bronchodilator use was observed in $32.1 \%$ of the population tested, a common finding in both patients with asthma and those with COPD. Since we did not include participants who were unobstructed in 2005 in the follow-up study, we cannot confirm how many might have changed to an obstructed category. However, random variation around the cut-off for $\mathrm{FEV}_{1} / \mathrm{FVC}$ of 0.7 is well described. ${ }^{[22]} \mathrm{An}$ additional reason for the reversal of the $\mathrm{FEV}_{1} / \mathrm{FVC}$ from obstructed to non-obstructed is the unexpectedly higher decline in FVC in participants with milder CAO. Lastly, some participants may have improved either spontaneously, owing to removal from exposures (e.g. smoking cessation), or from use of medication. The significance of the change in FVC during follow-up lies in the fact that low vital capacity has been shown to be correlated with poverty and is a better predictor of mortality in COPD than airflow obstruction (percentage of predicted $\left.\mathrm{FEV}_{1}\right) \cdot{ }^{[23]}$

A finding of concern for public health and policy-makers is the very low level of treatment reported in participants with symptomatic and severe COPD. The median SGRQ total score (33.4) reflects high levels of dyspnoea and chronic cough among participants. The current recommendation is that patients with scores of $\geq 25$ warrant treatment for CAO. ${ }^{[3]}$ Additionally, $30.2 \%$ of participants were in GOLD stages 3 (severe) or 4 (very severe), yet only $3.7 \%$ reported use of a long-acting bronchodilator (LABA) as recommended in guidelines. LABAs and inhaled corticosteroids separately and in combination are available for prescription by specialist pulmonologists in the SA state sector, but access to specialised care is limited, denying patients effective treatment. Furthermore, long-acting antimuscarinics, the most widely used and most highly effective long-acting bronchodilator worldwide, are currently not available in state healthcare facilities in the Western Cape. The low levels of treatment may reflect both underdiagnosis in our population-based study and inadequate access to medications. These factors may account for much of the morbidity and poor outcomes of participants with CAO in our study. Our study highlights the plight of such patients and the need for access to effective treatments to be made available to patients with COPD.

The association between a history of previous PTB and CAO is described in many population-based studies, in which the pooled odds ratio (OR) of 3.05 for this association is estimated. ${ }^{[11,24]}$ The reason for this association and causality remains unclear. ${ }^{[25]}$ Significant observations in the current study related to this association are, first, that previous PTB was not associated with increased mortality (OR 1.92 (95\% confidence interval $0.81-4.58)$ ). Second, 9.3\% of participants developed acute $\mathrm{TB}$ in the 5 years between the studies, yielding an annual incidence rate (1 860/100 000 population) more than double that of the local community. This finding is in keeping with other studies, suggesting that COPD may predispose to TB infection and disease. ${ }^{[26,27]}$ Third, more than half of those with previous PTB reported having their first episode of TB before the age of 40 years, lending weight to the proposal that TB may precede the development of $\mathrm{CAO}$, and may be causative. However, this association could be bidirectional; CAO may be a consequence of TB, and a risk factor for the development of subsequent TB.

None of our enrolled participants were HIV-positive, which may appear unusual in SA. This may be explained by the age of the participant cohort, the relatively low prevalence of HIV infection in Cape Town, and the stable nature of the study community.

\section{Study limitations}

This study has a number of important limitations. First, its small size limits the strength of the findings. Second, the response rate was limited. Of the original cohort, $22.4 \%$ were alive but not enrolled. Third is the limited details on causes of deaths, unknown in almost half the cases. Fourth is lack of representivity of this low- to middleincome community of people of mixed race to the SA population in general, which limits the application of the findings to other areas of the country.

\section{Conclusions}

This 5-year population-based follow-up study of patients with CAO, most of which may be defined as COPD, in a high-prevalence setting in SA confirms the seriousness of this condition and the gaps in its management. It confirms progression, particularly of FVC in patients with milder disease, which might be amenable to preventive measures (removal from harmful exposures, including smoking cessation) and effective treatment. It identifies the high symptom burden and mortality associated with this condition and the interaction with $\mathrm{PTB}$, and points to the influence of very low levels of treatment currently being offered to patients with COPD. These results identify the urgent need for further studies of COPD in SA, examining its prevalence in other population groups and settings, the clinical burden and mortality, and gaps in diagnosis and treatment that need to be addressed as part of the current push to address non-communicable diseases.

Acknowledgements. We acknowledge the contribution of staff in the Lung Clinical Research Unit of the University of Cape Town Lung Institute and the Desmond Tutu TB Centre, Stellenbosch University, and the subjects who participated in the study.

Author contributions. Study conception and design: BWA, EDB, CBC, NB; data acquisition: BWA, RG, MB, HO, LT-B, GLC, RvZ-S; physiology analysis: BWA, $\mathrm{EDB}, \mathrm{CBC}$; data interpretation: BWA, EDB, NB, CBC; manuscript preparation: all.

Funding. Financial support was received from the UCT Lung Institute, a Discovery Foundation academic scholarship, a South African Medical Research Council scholarship and a South Africa Thoracic Society/AstraZeneca scholarship. LT-B was funded by a grant from the Portuguese Foundation for Science and Technology (grant no. FCT-FRH/ BSAB/976/2010).

Conflicts of interest. None. 
1. Lozano R, Naghavi M, Foreman K, et al. Global and regional mortality from 235 causes of death for 20 age groups in 1990 and 2010: A systematic analysis for the Global Burden of Disease Study 2010 Lancet 2012;380(9859):2095-2128. https://doi.org/10.1016/S0140-6736(12)61728-0

2. World Health Organization. Chronic Obstructive Pulmonary Disease (COPD). Fact Sheet No. 315 http://www.who.int/mediacentre/factsheets/fs315/en/ (accessed 15 June 2017).

3. Global Initiative for Chronic Obstructive Lung Disease. Global Strategy for the Diagnosis Management, and Prevention of Chronic Obstructive Pulmonary Disease (2017 Report). http:// goldcopd.org/gold-2017-global-strategy-diagnosis-management-prevention-copd/ (accessed 18 March 2017).

4. Burney PGJ, Patel J, Newson R, Minelli C, Naghavi M. Global and regional trends in COPD mortality 1990 - 2010. Eur Respir J 2015;45(5):1239-1247. https://doi.org/10.1183/09031936.00142414

5. Fletcher C, Peto R. The natural history of chronic airflow obstruction. BMJ 1977;1(6077):1645-1648. https://doi.org/10.1136/bmj.1.6077.1645

6. Lange P, Celli B, Agustí A, et al. Lung-function trajectories leading to chronic obstructive pulmonary disease. N Engl J Med 2015;373(2):111-122. https://doi.org/10.1056/NEJMoa1411532

7. Vestbo J, Edwards LD, Scanlon PD, et al. Changes in forced expiratory volume in 1 second over time in COPD. N Engl J Med 2011;365(13):1184-1192. https://doi.org/10.1056/NEJMoal 105482

8. Casanova C, de Torres JP, Aguirre-Jaíme A, et al. The progression of chronic obstructive pulmonary disease is heterogeneous: The experience of the BODE cohort. Am J Respir Crit Care Med 2011;184(9):1015-1021. https://doi.org/10.1164/rccm.201105-08310C

9. Tashkin DP, Celli B, Senn S, et al. A 4-year trial of tiotropium in chronic obstructive pulmonary disease. N Engl J Med 2008;359(15):1543-1554. https://doi.org/10.1056/NEJMoa0805800

10. Jithoo A. Respiratory symptoms and chronic obstructive pulmonary disease. Prevalence and risk factors in a predominantly low-income urban area of Cape Town, South Africa. PhD thesis. Cape Town: University of Cape Town, 2006

11. Buist AS, McBurnie MA, Vollmer WM, et al. International variation in the prevalence of COPD (the BOLD Study): A population-based prevalence study. Lancet 2007;370(9589):741-750. https://doi. org/10.1016/S0140-6736(07)61377-4

12. Amaral AFS, Coton S, Kato B, et al. Tuberculosis associates with both airflow obstruction and low lung function: BOLD results. Eur Respir J 2015;46(4):1104-1112. https://doi.org/10.1183/13993003.02325-2014 3. Miller MR. Standardisation of spirometry. Eur Respir J 2005;26(2):319-338. https://doi.org/10.1183 09031936.05.00034805

14. Hankinson JL, Odencrantz JR, Fedan KB. Spirometric reference values from a sample of the general U.S. population. Am J Respir Crit Care Med 1999;159(1):179-187. https://doi.org/10.1164/ ajrccm.159.1.9712108

15. De Wit E, Delport W, Rugamika CE, et al. Genome-wide analysis of the structure of the South Africa coloured population in the Western Cape. Hum Genet 2010;128(2):145-153. https//doi.org/10.1007/ s00439-010-0836-1
16. Allwood BW, Gillespie R, Galperin-Aizenberg M, et al. Obstructive pulmonary disease in patients with previous tuberculosis: Pathophysiology of a community-based cohort. S Afr Med J 2017;107(5):44045. https://doi.org/10.7196/SAMJ.2017.v107i5.12118

17. Allwood BW, Goldin J, Said-Hartley Q, et al. Assessment of previous tuberculosis status using questionnaires, chest X-rays and computed tomography scans. Int J Tuberc Lung Dis 2015;19(12):14351440. https://doi.org/10.5588/ijtld.14.0992

18. Statistics South Africa. Mortality and causes of death in South Africa, 2011: Findings from death notification. Statistical release P0309.3. Pretoria: Stats SA, 2014. http://www.statssa.gov.za/ publications/P03093/P030932013.pdf (accessed 12 June 2017).

19. Folb N, Timmerman V, Levitt NS, et al. Multimorbidity, control and treatment of noncommunicable diseases among primary healthcare attenders in the Western Cape, South Africa. S Afr Med J 2015;105(8):642-647. https://doi.org/10.7196/SAMJnew.8794

20. Sitas F, Egger S, Bradshaw D, et al. Differences among the coloured, white, black, and other South African populations in smoking-attributed mortality at ages $35-74$ years: A case-control study of 481,640 deaths. Lancet 2013;382(9893):685-693. https://doi.org/10.1016/S0140-6736(13)61610-4

21. Casanova C, de Torres JP, Aguirre-Jaíme A, et al. The progression of chronic obstructive pulmonar disease is heterogeneous: The experience of the BODE cohort. Am I Respir Crit Care Med 2011:184(9):1015-1021. https://doi.org/10.1164/rccm.201105-08310C

22. Akkermans RP, Berrevoets MA, Smeele IJ, et al. Lung function decline in relation to diagnostic criteria for airflow obstruction in respiratory symptomatic subjects. BMC Pulm Med 2012;12(1):12. https:// doi.org/10.1186/1471-2466-12-12

23. Burney $\mathrm{P}$, Jithoo $\mathrm{A}$, Kato $\mathrm{B}$, et al. Chronic obstructive pulmonary disease mortality and prevalence: The associations with smoking and poverty - a BOLD analysis. Thorax 2014;69(5):465-473. https://doi. org/10.1136/thoraxjnl-2013-204460

24. Byrne AL, Marais BJ, Mitnick CD, Lecca L, Marks GB. Tuberculosis and chronic respiratory disease: A systematic review. Int J Infect Dis 2015;32:138-146. https://doi.org/10.1016/j.ijid.2014.12.016

5. O’Toole RF, Shukla SD, Walters EH. TB meets COPD: An emerging global co-morbidity in human lung disease. Tuberculosis 2015;95(6):659-663. https://doi.org/10.1016/j.tube.2015.08.005

26. Dong Y-H, Chang C-H, Wu F-LL, et al. Use of inhaled corticosteroids in patients with chronic obstructive pulmonary disease and the risk of tuberculosis and influenza: A systematic review and meta-analysis of randomized controlled trials. Chest 2014;145(6):1286-1297. https://doi.org/10.1378/ chest.13-2137

27. Hung C-L, Chien J-Y, Ou C-Y. Associated factors for tuberculosis recurrence in Taiwan: A nationwide nested case-control study from 1998 to 2010. PLoS One 2015;10(5):e0124822. https://doi.org/10.1371/ journal.pone.0124822

Accepted 31 August 2017. 